\title{
Where Have All the Domestic Graduate Students Gone?
}

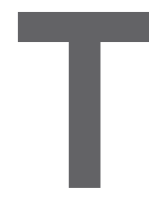

HE U.S. HAS been a magnet for technical talent from all over the world since World War II. For example, immigrants have been awarded nearly $40 \%$ of the Nobel Prizes won by Americans in chemistry, medicine, and physics since 2000. Tech industry giants Apple, Amazon, Facebook, and Google were all founded by first- or second-generation immigrants. As Sudip Parikh, the CEO of the American Association for the Advancement of Science, wrote in a recent Science editorial, "Immigrants make America great."

Yet in the past couple of months, the U.S. Government has taken actions to restrict immigration of technical workforce into the country. In June 2020, President Trump temporarily suspended new work visas and barred hundreds of thousands of foreigners from seeking employment in the U.S. In early July 2020, the Trump Administration announced that international students at U.S. universities operating entirely online may not take a full online course load and remain in the U.S.

These actions by the U.S. Government, which the science and engineering community strongly objects to, have the potential of resulting in a dramatic reduction in the number of international graduate students in U.S. universities. This will be compounded by barriers to international mobility due to COVID-19. This reduction will have a devastating impact on U.S. graduate programs in computing (as well as other science and engineering programs). According to the U.S. National Science Foundation survey of graduate and postdoctoral students, about $80 \%$ of graduate students in U.S. computer science and engineering programs are international students, and about $90 \%$ of U.S. graduate programs in computer science and engineering have a majority of international students.

The loss of international professional master's students will result in a serious loss of income to U.S. universities, at a time when the economic crisis inflicted by COVID-19 already unleashed a heavy price on U.S. institutions. But the loss of international doctoral students would significantly diminish the research capability of graduate programs in science and engineering. After all, doctoral students, supervised by principal investigators, carry out the bulk of research in science and engineering in academic departments.

There is no question that making the U.S. less attractive to international graduate students in science and engineering would have long-term adverse consequences on U.S. technology leadership and competitiveness. An obvious question is why the U.S. Government would choose to take actions that are so detrimental to the U.S. economy. But a deeper question is how the U.S. has become so dependent on international students as the major workforce of its academic science and engineering research enterprise.

The common experience of a doctoral-admission committee in computing is that there are not enough qualified domestic doctoral applicants to fill the "needs" of their doctoral programs, where these needs are defined by the number of teaching and research assistantships offered by these programs. Graduate programs admit so many international students not only because they have strong international applicants, but mainly because they do not have enough qualified domestic applicants. We must conclude the doctoral career track is simply not attractive enough to U.S. undergrad CS students.

Attaining a doctoral degree is a formidable undertaking, as any follower of Ph.D. Comics would undoubtedly know. But when a country fails systemically to create an adequate pipeline for its technical workforce, it suggests the existence of a systemic problem. Doctoral programs have a crucial dual role. On one hand, they prepare future faculty members, who will educate the next generation of computing professionals. On the other hand, they educate an advanced workforce for the computingtechnology industry. Doctorate holders in computing are in high demand. The economy needs them. The lack of an adequate pipeline is a bug, not a feature!

But instead of acknowledging the existence of this problem and trying to address it, we have found a way to meet our departmental needs by recruiting and admitting international students. That is, the supply of a steady stream of highly qualified international applicants allowed us to ignore the inadequacy of the domestic doctoral pipeline.

We must object to the harmful policies of the U.S. Government. Even though the July policy has been rescinded at press time, and independent of the final outcome, the current crisis provides us with an opportunity for introspection and self-study. We need to understand the roots of the problem and propose remedies. The U.S. should welcome international doctoral students because they enrich our doctoral programs, not because they sustain our doctoral programs.

Follow me on Facebook and Twitter.c

Moshe Y. Vardi (vardi@cs.rice.edu) is the Karen Ostrum George Distinguished Service Professor in Computational Engineering and Director of the Ken Kennedy Institute for Information Technology at Rice University, Houston, TX, USA $\mathrm{He}$ is the former Editor-in-Chief of Communications. 